Article

\title{
Temporal Variation and Spatial Structure of the Kuroshio-Induced Submesoscale Island Vortices Observed from GCOM-C and Himawari-8 Data
}

\author{
Po-Chun Hsu ${ }^{\circledR}$, Chia-Ying Ho, Hung-Jen Lee ${ }^{\circledR}$, Ching-Yuan Lu and Chung-Ru Ho * \\ Department of Marine Environmental Informatics, National Taiwan Ocean University, Keelung 20224, Taiwan; \\ hpochun@ntou.edu.tw (P.-C.H.); 20781001@ntou.edu.tw (C.-Y.H.); lecgyver@mail.ntou.edu.tw (H.-J.L.); \\ 20681002@ntou.edu.tw (C.-Y.L.) \\ * Correspondence: b0211@mail.ntou.edu.tw
}

Received: 13 February 2020; Accepted: 8 March 2020; Published: 9 March 2020

\begin{abstract}
Dynamics of ocean current-induced island wake has been an important issue in global oceanography. Green Island, a small island located off southeast of Taiwan on the Kuroshio path was selected as the study area to more understand the spatial structure and temporal variation of well-organized vortices formed by the interaction between the Kuroshio and the island. Sea surface temperature (SST) and chlorophyll-a (Chl-a) concentration data derived from the Himawari-8 satellite and the second generation global imager (SGLI) of global change observation mission (GCOM-C) were used in this study. The spatial SST and Chl-a variations in designed observation lines and the cooling zone transitions on the left and right sides of the vortices were investigated using $250 \mathrm{~m}$ spatial resolution GCOM-C data. The Massachusetts Institute of Technology general circulation model $(\mathrm{MITg} \mathrm{cm})$ simulation confirmed that the positive and negative vortices were sequentially detached from each other in a few hours. In addition, totals of 101 vortexes from July 2015 to December 2019 were calculated from the 1-h temporal resolution Himawari-8 imagery. The average vortex propagation speed was $0.95 \mathrm{~m} / \mathrm{s}$. Totals of 38 cases of two continuous vortices suggested that the average vortex shedding period is $14.8 \mathrm{~h}$ with $1.15 \mathrm{~m} / \mathrm{s}$ of the average incoming surface current speed of Green Island, and the results agreed to the ideal Strouhal-Reynolds number fitting curve relation. Combined with the satellite observation and numerical model simulation, this study demonstrates the structure of the wake area could change quickly, and the water may mix in different vorticity states for each observation station.
\end{abstract}

Keywords: island wake; vortex; sea surface temperature; chlorophyll-a; Himawari-8; GCOM-C

\section{Introduction}

\subsection{Background}

Island wakes have been studied for many years in the global oceans. Different driving forces cause this phenomenon and these wakes have different characteristics according to the island's scale and water depth [1-4]. Green Island, a small island located off southeast of Taiwan, is on the path of the Kuroshio to the East China Sea (Figure 1). Green Island is an obstacle on the "ocean highway". Kuroshio passes Green Island and causes a change in flow fields, such as the Von Kármán vortex street [5-9]. In the lee of the island, a high chlorophyll-a (Chl-a) concentration and low sea surface temperature (SST) wake region can be formed [8]. This recirculation area contained a cyclonic/anticyclonic vorticity pair accompanied by a density overturn and water upwelling [9]. The increased surface Chl-a concentration and decreased SST are induced by upwelling from deep-layer waters in the island wakes $[5,9]$. Like a supply depot for marine life, the SST fronts between the wake area and the Kuroshio could provide 
favorable conditions for marine fishing grounds. The island wake induced upwelling, downstream mixing and eddies could result in phytoplankton biomass and chlorophyll concentrations increased near the island, which is called the island mass effect [10]. Enhanced phytoplankton can elicit a biological response in fishes, carbon cycles and food web. There are more than 600 species of fish around Green Island [11]. It is also an important habitat for a coral reef [12]. Therefore, studying the wake of the island is an important issue.

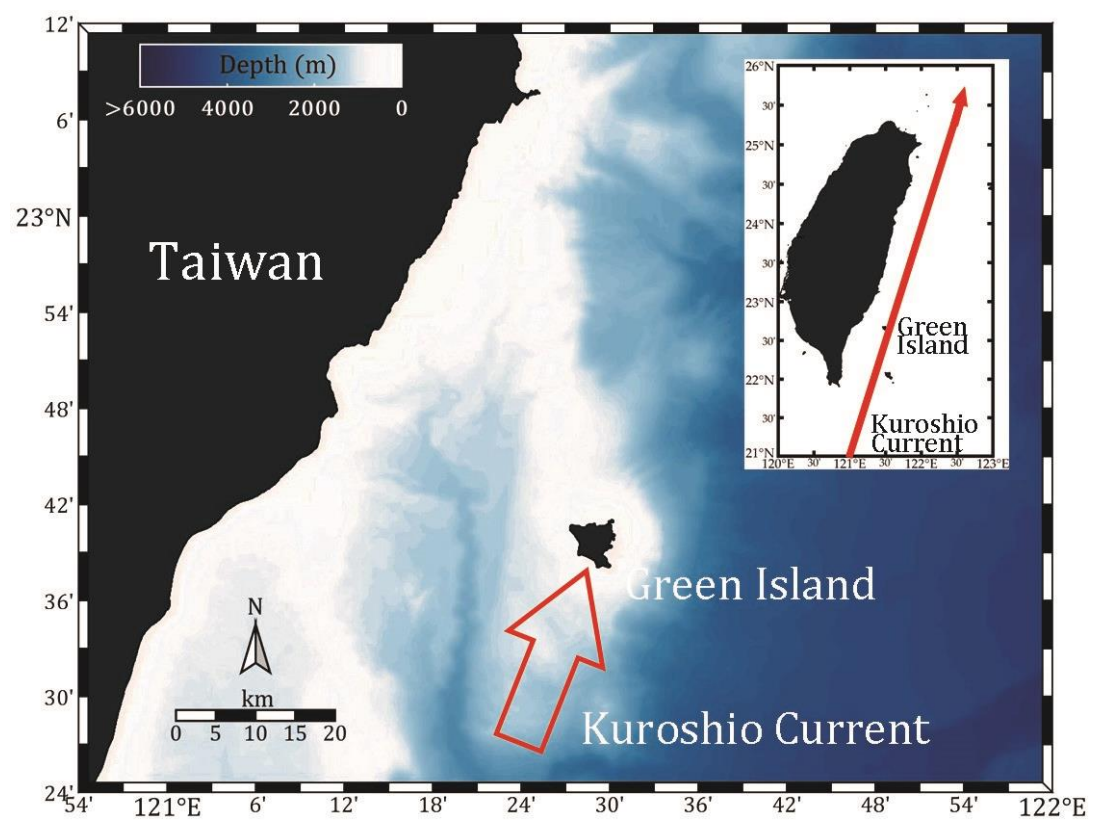

Figure 1. The bottom topography around Green Island and the path of the Kuroshio (red line and arrow).

Previous researches have used high-resolution satellite imagery, acoustic Doppler current profilers, cruise observations, and numerical models to analyze the Green Island wakes [5,8,9]. An island-induced ocean vortex train (IOVT) [7] is formed leeward of Green Island by the incoming Kuroshio [8]. When an ocean vortex forms, observations from the moored acoustic Doppler current profiler (ADCP) suggest that the velocity on the western side of Green Island increases [8]. In addition, the IOVT shows variability under wind forcing $[8,13]$. Southerly wind helps the wake expand because it lies in the same direction as the incoming current, while the northerly wind compresses the development of the wake $[8,13]$. The island wakes influence the area of SST drops, which could extend $35 \mathrm{~km}$ downstream of Green Island, and vortex shedding could propagate as far as $80 \mathrm{~km}$ downstream of the island [9]. Research on underwater island wakes suggests that a depth range with a high inverted Reynolds number is supposed to have density overturns and a high Thorpe scale with a turbulent kinetic energy dissipation rate of $\mathrm{O}\left(10^{-6}-10^{-5}\right) \mathrm{W} / \mathrm{kg}$, which corresponds to an eddy diffusivity of $\mathrm{O}\left(10^{-2}-10^{-1}\right) \mathrm{m}^{2} / \mathrm{s}$ [9]. Numerical model research has suggested that the vortex street features are adapted by inertial and barotropic instabilities [14], and the shedding period of the vortex is synchronized to a tidal period [15].

\subsection{Objectives}

Although there are many studies on the Green Island wakes, the dynamics of these wakes remain difficult to be determined. Cruise and instrument observations can measure detailed data on the underwater wakes, but the advantages of remote sensing could be used to obtain accurate and simultaneous data for sea surface wakes. Before the next measurement, it is necessary to clarify the spatial scale and dynamic processes of the wakes on the island surface using satellite data. Only by determining the feedback of the surface seawater to the wake can a researcher accurately design the observation line and measurement frequency by cruise. 
The purpose of this study is to use the satellite data to obtain novel results of the Green Island wake in order to make up for the shortcomings of in-situ measurements and the inability for the model to be measured. They include (1) designing the imaginary lines to describe the Chl-a and SST response to the wake from the second generation global imager (SGLI) data on the global change observation mission (GCOM-C), (2) using the Himawari-8 SST data to calculate the wake vortex detachment propagating speed and using the maximum cross-correlation (MCC) method to estimate the incoming velocity of the wake, (3) calculating and discussing the Strouhal number-Reynolds number relationship of wake dynamics.

Understanding the spatial structure of surface wakes can help determine the biological hotspots in the wake area and improve knowledge of oceanic wakes. The evolution process of a wake can be separated into four types, including a wake occurring alone, a wake occurring with a tail stretching downstream, an S-shaped meandering wake, and a wake with a small cyclonic/anticyclonic vortex pair downstream [9]. However, the detailed spatial structures of each type of wake remain unknown. The SGLI observations with $250 \mathrm{~m}$ spatial resolution will improve our understanding of ocean change mechanisms through long-term monitoring. The use of imaginary design observation lines helps to understand the sea surface characteristics of the wake region at the same time but different locations.

Using high spatial resolution sun-synchronous satellite data could successfully detect the SST drop in the cold wake area but could not further track the process of vortex movement in continuous an hour interval due to the lack of a high temporal resolution [9]. To study the dynamics of island wakes, the most important factor is to solve the setting of the two major parameters, the Strouhal number $(S t)$ and the Reynolds number $(R e)$, as well as the propagation velocity of the cold vortex $\left(U_{e}\right)$. However, it is very difficult to measure these two parameters with a cruise observation in the ocean. For the Green Island area, there must be a certain number of research surveys to measure the current velocity and SST variations in front of and downstream of the island. Previous studies applied parameters such as the estimated distance between two consecutive vortices and the radius of vortices from Synthetic Aperture Radar (SAR) images to the empirical equation to obtain the incoming current velocity and the propagation velocity of the vortex [16]. However, SAR imagery is a snapshot image, which does not have a high temporal resolution or a sufficient image, making it difficult to engage in a long-term observation of wake dynamics. With advances in satellite imagery, the Himawari-8 geostationary satellite data provide a useful solution to the small cold vortex detachment process and detect the vortex trajectory in wake dynamics. Understanding the relationship between $S t$ and $R e$ and the speed and period of cold vortex detachment can be useful for improving numerical simulations.

Recognizing the Green Island wake not only requires us to physical discuss wake dynamics but also to investigate the development of ocean environmental sustainability. The results could help marine fisheries and chemists better understand the status of this area.

\section{Materials and Methods}

The process of this study was divided into three steps. Firstly, the in-situ observations were used to present the underwater structure in the wake region. Secondly, the detailed structure of the surface wake was analyzed using the SGLI data from the GCOM project. Finally, the Himawari-8 imagery was used to analyze the vortices movement process, and the MITgcm (Massachusetts Institute of Technology General Circulation Model) numerical model was used to simulate the wake variation.

The MCC method was applied to hourly Himawari-8 SST images to calculate the incoming surface current velocity for Green Island $\left(22.5^{\circ}-22.7^{\circ} \mathrm{N}, 122.3^{\circ}-122.5^{\circ} \mathrm{E}\right)$. The principle of the MCC method is to find the maximum correlation between a template image of SST patterns and the selected search image in the next time interval. In this way, we can determine how far the center point of the template image has moved in an hour and estimate the flow velocity. The MCC method needs to adjust the parameter selection settings for different research scopes [17-19]. In this study, the pixel resolution of $2 \mathrm{~km}$ was increased to $1 \mathrm{~km}$ by interpolation. Considering the complex flow field variations and spatial scale of the SST variation in southeast Taiwan, the four template images $(7 \times 7,9 \times 9,11 \times 11$, and 
$13 \times 13$ pixels) and the sides of the search image $(7 \mathrm{~km}$ to each direction from the center of the template image) were chosen. In this study, the acceptance criteria for the cross-correlation coefficient should be larger than 0.9. With this parameter set, the minimum and the maximum speeds in the estimate were about $0.28 \mathrm{~m} / \mathrm{s}$ and $1.94 \mathrm{~m} / \mathrm{s}$, respectively. The maximum flow velocity per template image was selected as the flow velocity in this area. Finally, the average maximum speed of the four template images during each vortex shedding case was calculated.

\subsection{Sea Surface Temperature and Chlorophyll-a Concentration}

The GCOM-C, carrying an SGLI conducts surface and atmospheric measurements, such as measurements of clouds, aerosols, ocean color, vegetation, and snow and ice. The SGLI is an optical sensor capable of multi-channel observations at wavelengths from near-UV to thermal infrared and obtains global observation data once every 2 or 3 days. The SGLI data are provided by the Japan Aerospace Exploration Agency/National Aeronautics and Space Administration. The data are available from January 2018, with a $250 \mathrm{~m}$ spatial resolution. The standard product and algorithm handbooks can be found on https://suzaku.eorc.jaxa.jp/GCOM_C.

Himawari-8 is the 8th of the Himawari geostationary Japanese weather satellites operated by the Japan Meteorological Agency. Himawari-8 carries the Advanced Himawari Imager with a wide spectral range and very high spatial and 10-minute temporal resolutions. The research products of SST and Chl-a used in this paper were supplied by the P-Tree System, Japan Aerospace Exploration Agency (JAXA). The standard product can be found on https://www.eorc.jaxa.jp/ptree/index.html. The SST data (2 km spatial resolution) and Chl-a ( $5 \mathrm{~km}$ spatial resolution) are available from 7 July 2015, with a 1-h temporal resolution. The Himawari-8 data have good accuracy and have been applied to calculate short-term sea surface currents $[17,20]$.

\subsection{Ocean Currents}

OSCAR (Ocean Surface Current Analysis Real-time) contains near-surface ocean current estimates derived using quasi-linear and steady flow momentum equations and combining geostrophic, Ekman, and Stommel shear dynamics, and a complementary term from the surface buoyancy gradient, detailed calculations can be referred to the User's Handbook [21]. These data were collected from various satellites and in situ instruments and directly estimated from the sea surface height, surface vector wind, and SST. These data were generated by the Earth Space Research (ESR) and are available from October 1992 to present, with a 1/3 degree spatial resolution and a 5-day temporal resolution. The OSCAR third-degree resolution ocean surface currents (OSCAR_L4_OC_third-deg) data which can be accessed through the https://podaac.jpl.nasa.gov/dataset/OSCAR_L4_OC_third-deg from NASA PODAAC (Physical Oceanography Distributed Active Archive Center). The OSCAR data are highly associated and accurate with the global tropical moored buoy array, and it has also been successfully used to explore the island wake around Palau in the western tropical North Pacific Ocean $[1,22,23]$.

\subsection{Numerical Model}

MITgcm is a numerical model designed for the study of the atmosphere, ocean, and climate. The source code for this model can be download from http://mitgcm.org/. We used this model to solve the Navier-Stokes equations under hydrostatic and Boussinesq approximations using the finite volume method [24]. The south, north, and east directions of the model domain are open boundaries that use the Orlanski radiation condition [25]. The HYbrid Coordinate Ocean Model and the Navy Coupled Ocean Data Assimilation (HYCOM + NCODA) Global 1/12 degree analysis (GLBu0.08) was used for the initial background data and the boundary driving force in the model. In this study, the case of the summer season was based on the average of June to August from 2013 to 2018. These data can be download from https://www.hycom.org/. The study area in the model set is from $120.85^{\circ} \mathrm{E}$ to $122.5^{\circ} \mathrm{E}$ and from $22.25^{\circ} \mathrm{N}$ to $23.5^{\circ} \mathrm{N}$. The horizontal resolution is $500 \mathrm{~m}$. The model uses z-coordinates. There are 80 levels in the vertical direction. The top layer's thickness is $5 \mathrm{~m}$, and the other thicknesses 
increase at a $5.26 \%$ increase rate for each layer. The maximum depth is $5513 \mathrm{~m}$. The horizontal eddy viscosity is $40 \mathrm{~m}^{2} / \mathrm{s}$. The Laplacian diffusion of heat and salt laterally is $4 \mathrm{~m}^{2} / \mathrm{s}$. The vertical diffusion of temperature and salt depends on the buoyancy frequency [26].

\subsection{In-Situ Observation}

In-situ observations were conducted in November 2012 using R/V Ocean Researcher I (OR1) in the lee of Green Island (the datasets are available from http://www.odb.ntu.edu.tw/en/). Seven stations (A1-A7) were selected to detect the vertical layer of the island wake from the southeast coast of Taiwan across the Kuroshio and the wake area north of Green Island (see Figure 2a). The shipboard acoustic Doppler current profiler (Sb-ADCP) and Conductivity Temperature Depth (CTD) surveys were also collected during the cruise. The AquaTracka III fluorometer is used for in-situ detection of Chl-a, dissolved compounds re-emit a fraction of this energy as fluorescence at longer wavelengths when they absorb light and the intensity of fluorescence is directly proportional to the concentration. The measurement range of the $75 \mathrm{kHz}$ Sb-ADCP on board R/V OR1 was 16.56-650 m, with a bin size of $8 \mathrm{~m}$. It recorded the current velocity with 2 min ensembles averaged over 30 pings.
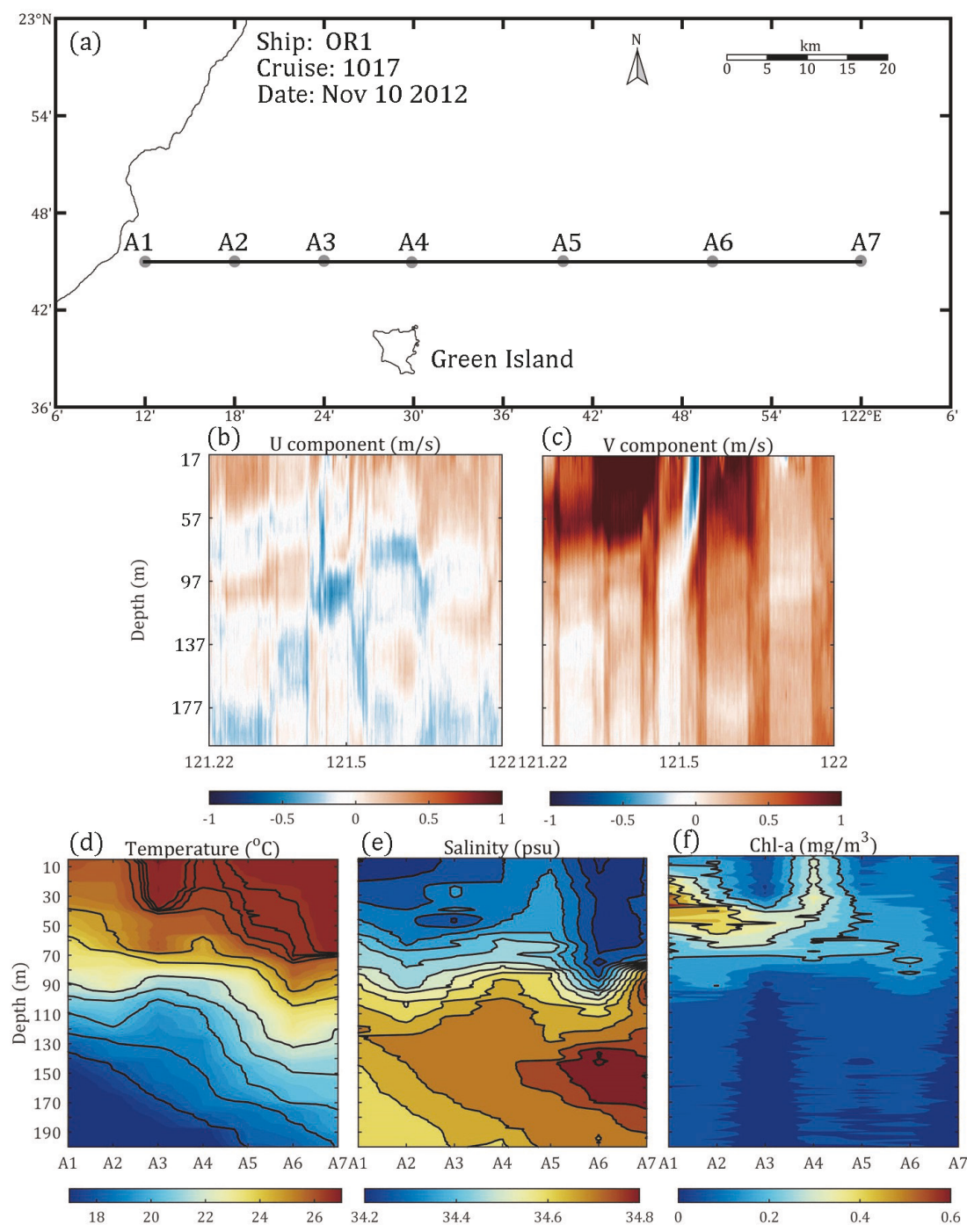

Figure 2. (a) The cruise experiment results with $(\mathbf{b}, \mathbf{c})$ velocity (U component positive in the east, $V$ component positive in the north), (d) temperature, (e) salinity, and (f) Chl-a from stations A1 to A7 on 10 November 2012. 


\section{Results}

\subsection{Field Experiment}

In this field experiment, the area between A4 and A5 was significantly affected by the island wake (Figure 2b,c), the isotherms and isohalines were uplifted from a depth of 100-120 $\mathrm{m}$ to the surface and the high Chl-a concentration water also upwelled from a depth of $70 \mathrm{~m}$ to the surface (Figure 2d-f). The wake water has lower SST, higher salinity, and higher Chl-a than the Kuroshio water. Moreover, the cruise observations could not measure the whole area of the wake at the same time, and the hydrological structure may be changed due to the dynamic nature of the island wakes. Therefore, remote sensing data with high temporal and spatial resolutions are recommended to discuss the surface structures of wakes.

\subsection{Spatial Structure of Island Wake}

In this section, GCOM-C SGLI data with a $250 \mathrm{~m}$ grid resolution are used to clarify these properties. Notably, these high-resolution cloud-free images are used to observe the spatial changes of SST and Chl-a at different locations throughout the wake region at the same time, and we designed imaginary observation lines for each case. In case 1, the classic and most common wake type with ten east-west observation lines is used to discuss the wake from the lee of Green Island to downstream (Figures 3 and 4). In case 2, an S-shaped meandering wake with three lines along the wake and one imaginary line are used to discuss the spatial-structural differences between two cold vortices (Figure 5). Case 3 offers a good comparative example to show the change of vorticity in the wake region during the vortex transition (Figure 6). A numerical model simulation is used to illustrate this phenomenon (Figure 7). Case 4 presents a typical theoretical von Kármán vortex street, but such phenomena rarely occur in an SST response (Figure 8).

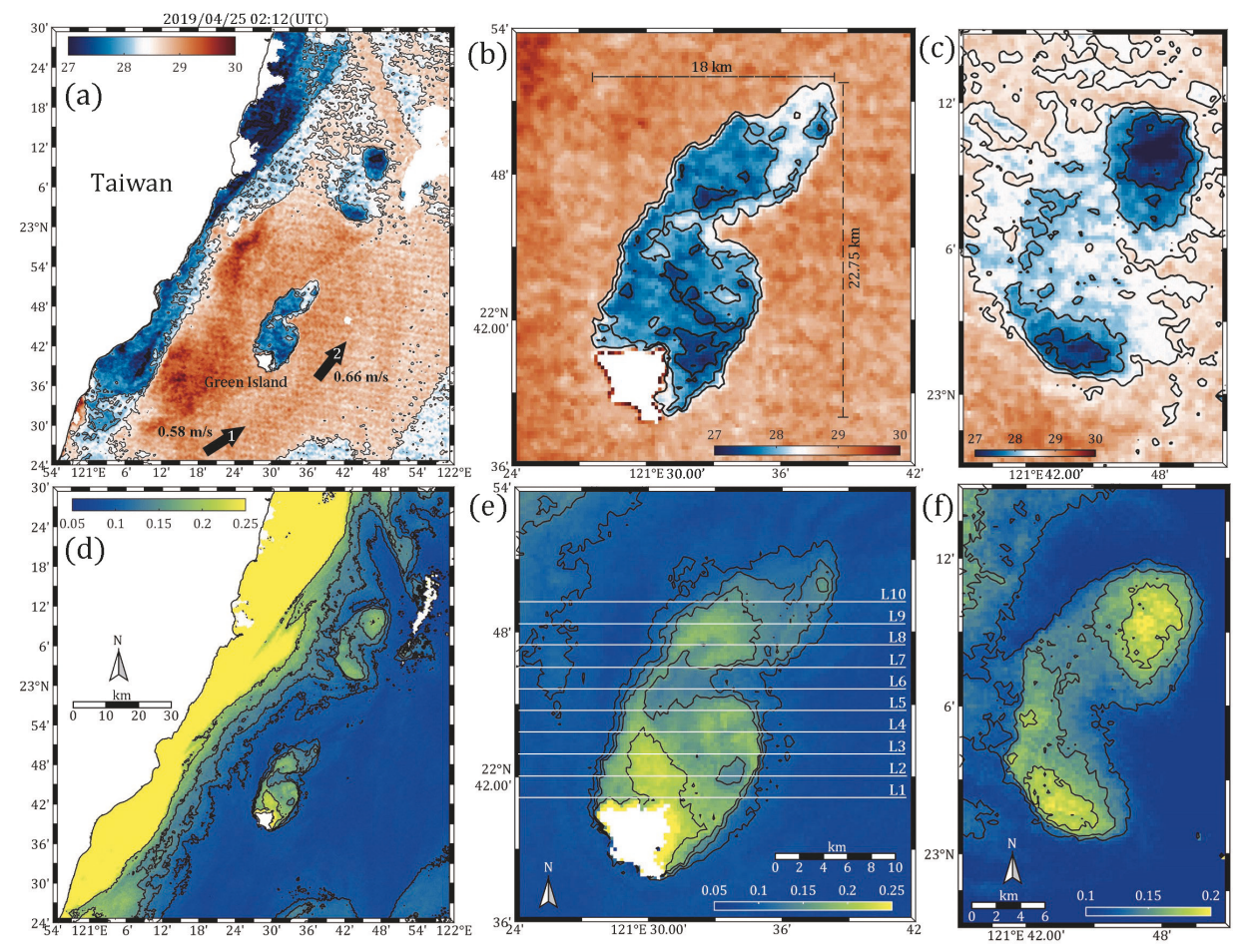

Figure 3. Case of the island vortex obtained from the global change observation mission (GCOM-C) second-generation global imager (SGLI) data taken at 02:12 (UTC), 25 April 2019. (a) Sea surface temperature (SST) $\left({ }^{\circ} \mathrm{C}\right),(\mathbf{b}, \mathbf{c})$ zoom in on vortices of $(\mathbf{a}, \mathbf{d})$ Chl-a $\left(\mathrm{mg} / \mathrm{m}^{3}\right),(\mathbf{e}, \mathbf{f})$ zoom in on vortices of (d). The black arrow in (a) is the current velocity from the OSCAR data. The first arrow $\left(22.33^{\circ} \mathrm{N}\right.$, $\left.121.33^{\circ} \mathrm{E}\right)$ has a speed of $0.58 \mathrm{~m} / \mathrm{s}$, and the second arrow $\left(22.67^{\circ} \mathrm{N}, 121.67^{\circ} \mathrm{E}\right)$ has a speed of $0.66 \mathrm{~m} / \mathrm{s}$. 


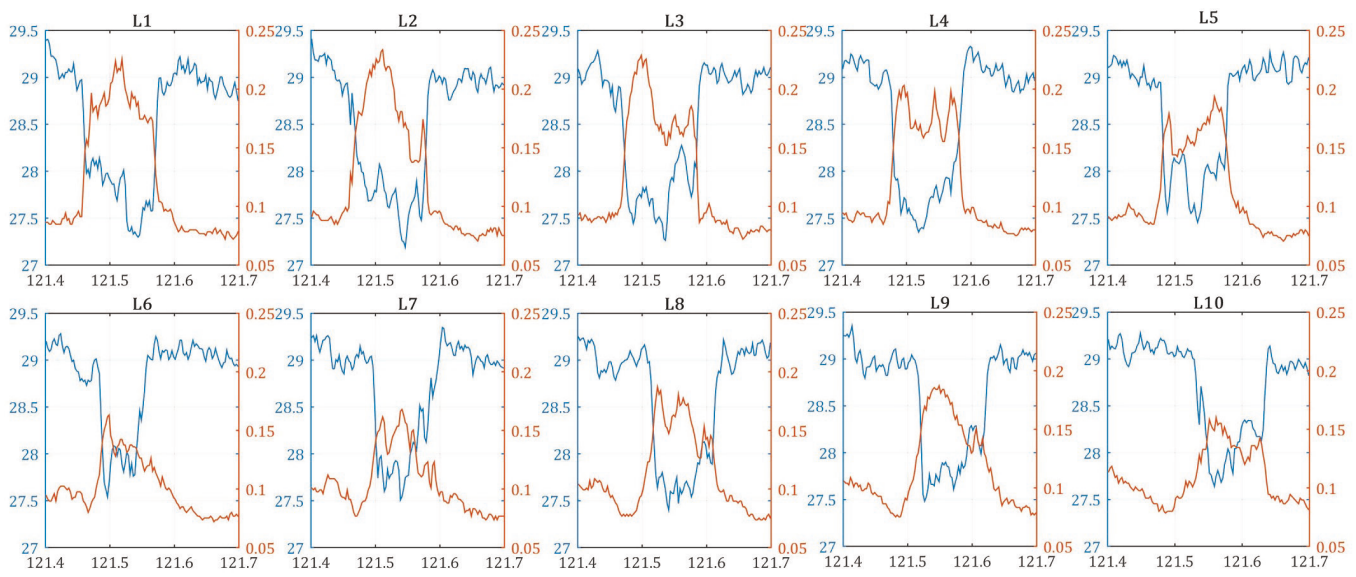

Figure 4. SST and chlorophyll-a (Chl-a) of L1 to L10 in Figure 3e.
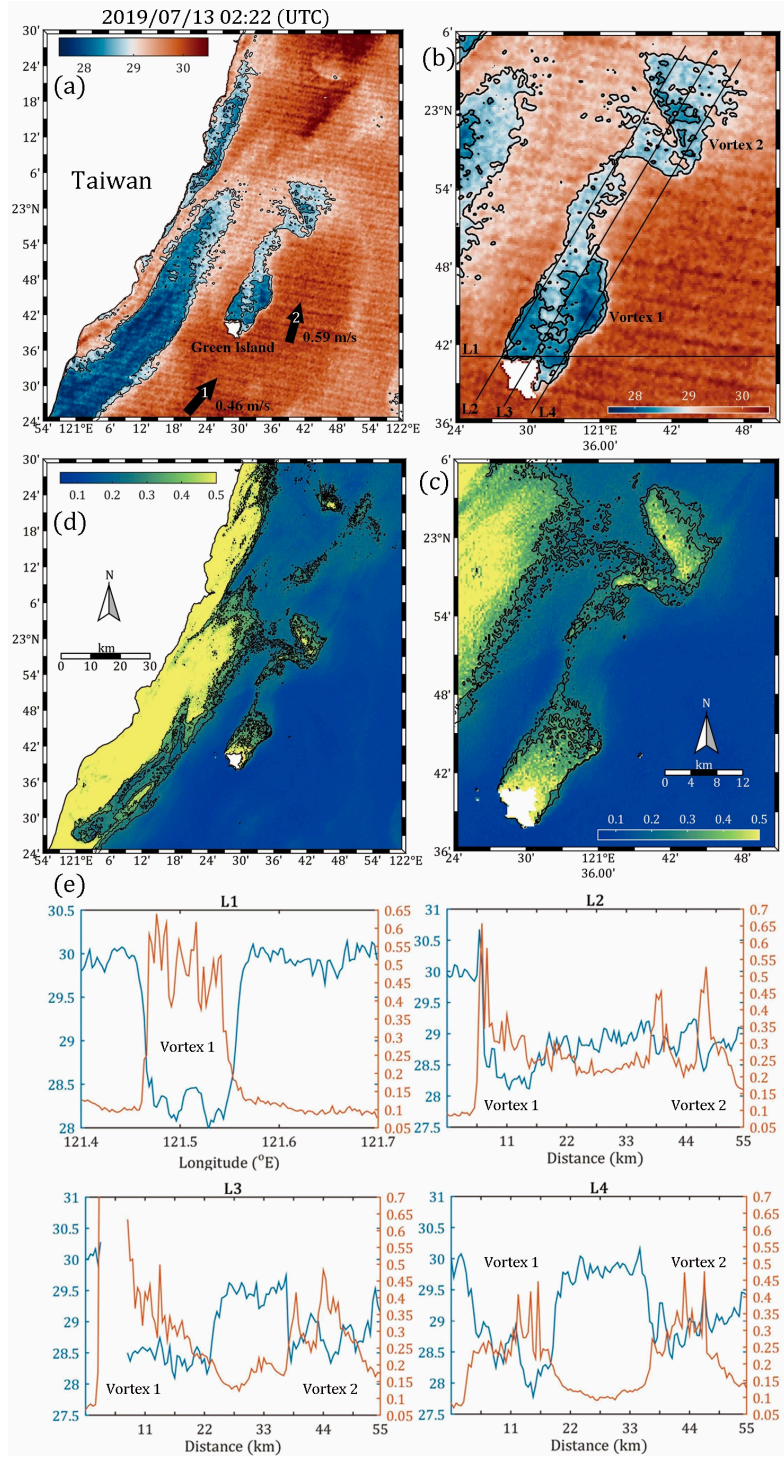

Figure 5. Case of the island vortex obtained from GCOM-C SGLI image taken at 02:22 (UTC), July 13, 2019. (a,b) SST $\left({ }^{\circ} \mathrm{C}\right),(\mathbf{c}, \mathbf{d}) \mathrm{Chl}-\mathrm{a}\left(\mathrm{mg} / \mathrm{m}^{3}\right)$, (e) SST, and Chl-a values of $\mathrm{L} 1$ to $\mathrm{L} 4$ in (b). The black arrow in (a) is the current velocity from the OSCAR data. The first arrow $\left(22.33^{\circ} \mathrm{N}, 121.33^{\circ} \mathrm{E}\right)$ has a speed of $0.46 \mathrm{~m} / \mathrm{s}$, and the second arrow $\left(22.67^{\circ} \mathrm{N}, 121.67^{\circ} \mathrm{E}\right)$ has a speed of $0.59 \mathrm{~m} / \mathrm{s}$. 

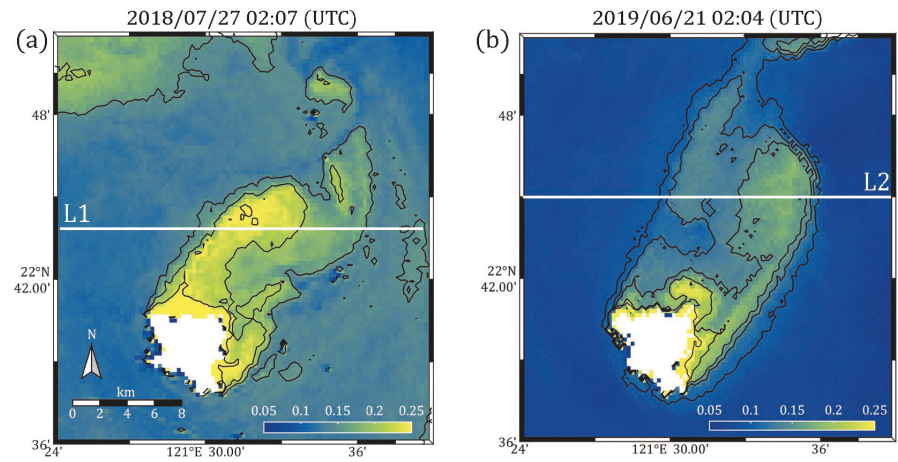
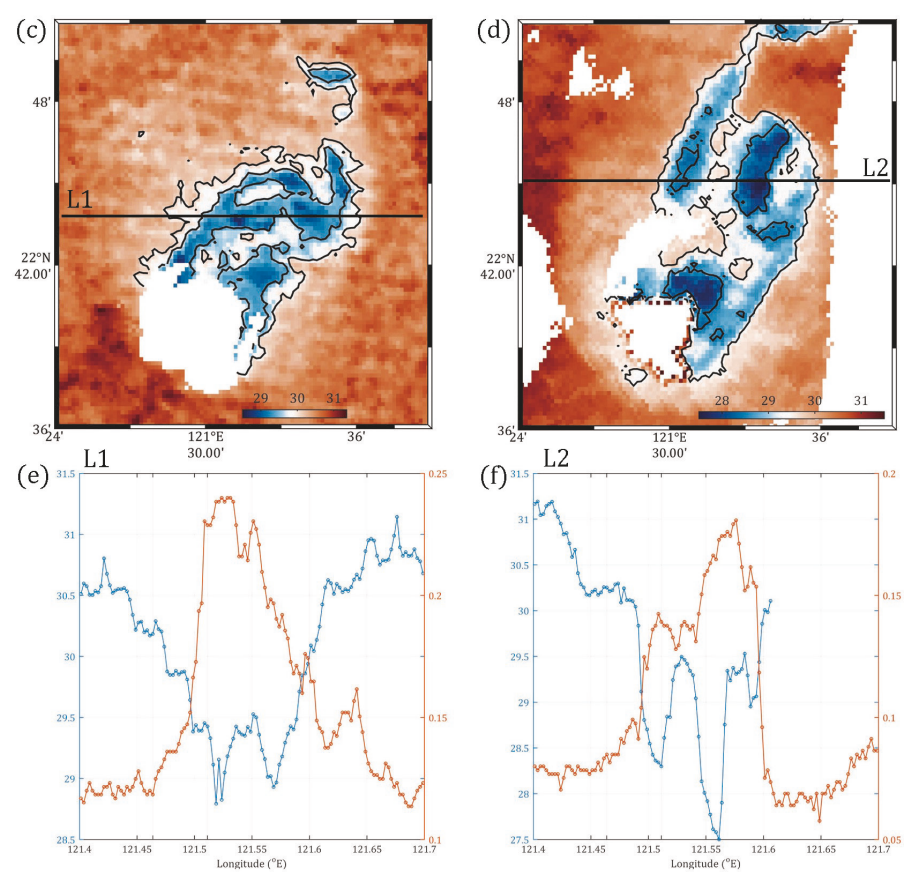

Figure 6. Two different spatially distributed vortices with $(\mathbf{a}, \mathbf{b}) \mathrm{Chl}-\mathrm{a}\left(\mathrm{mg} / \mathrm{m}^{3}\right)$ and $(\mathbf{c}, \mathbf{d})$ SST $\left({ }^{\circ} \mathrm{C}\right)$. Two cases obtained from GCOM-C SGLI data taken at 02:07 (UTC) 27 July 2018 (left) and at 02:04 (UTC) 21 June 2019 (right), (e,f) SST and Chl-a values of L1 and L2.

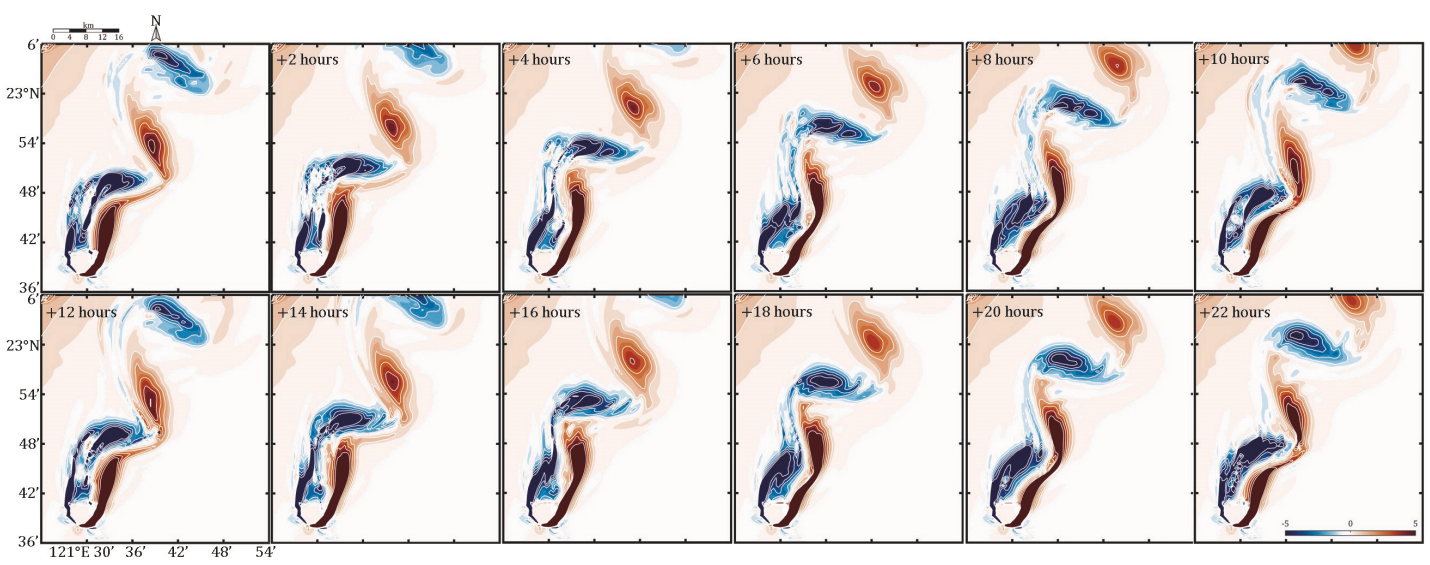

Figure 7. Results of the MITgcm numerical mode lasting one day. The background is the dimensionless parameter Ro. 


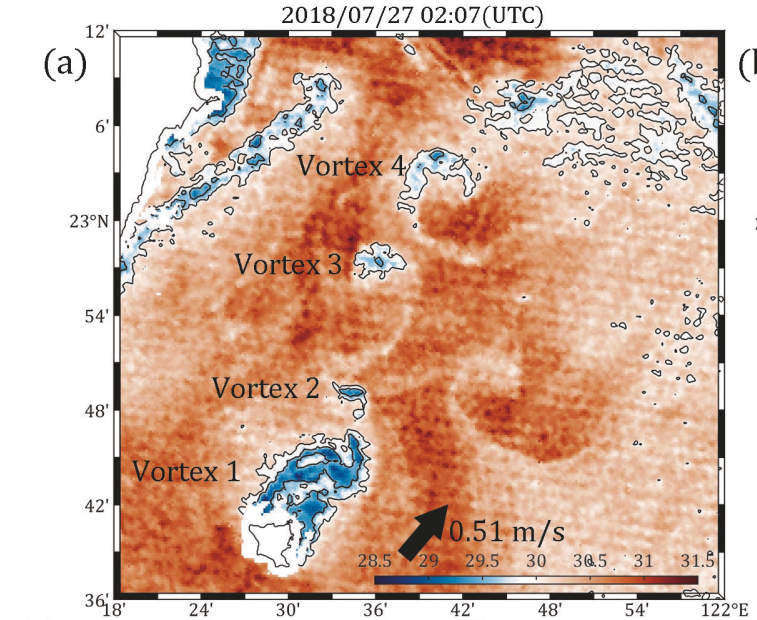

(c)

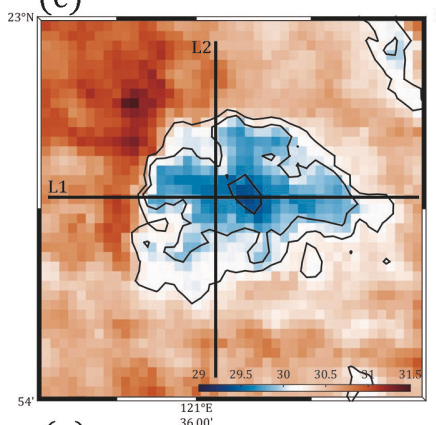

(e)

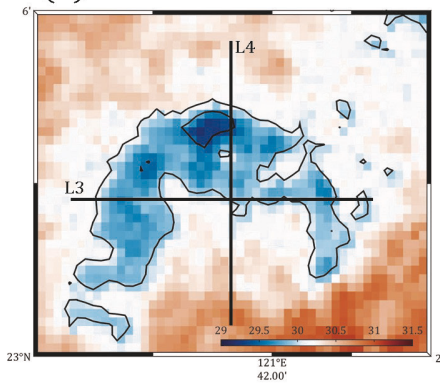

(d)

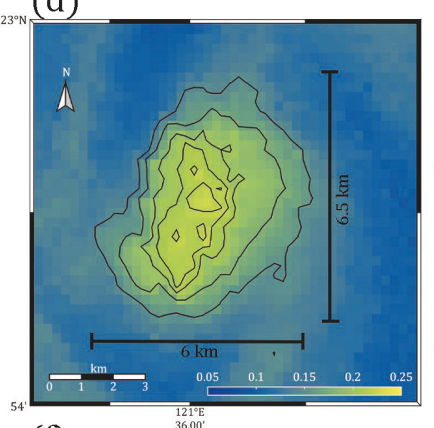

(f)

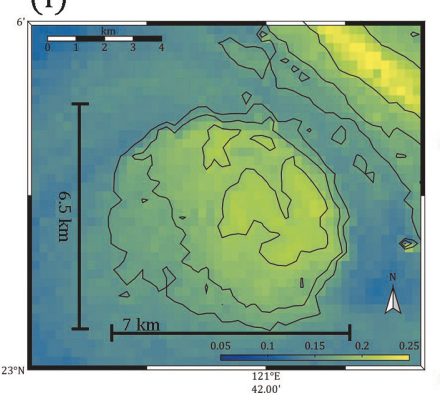

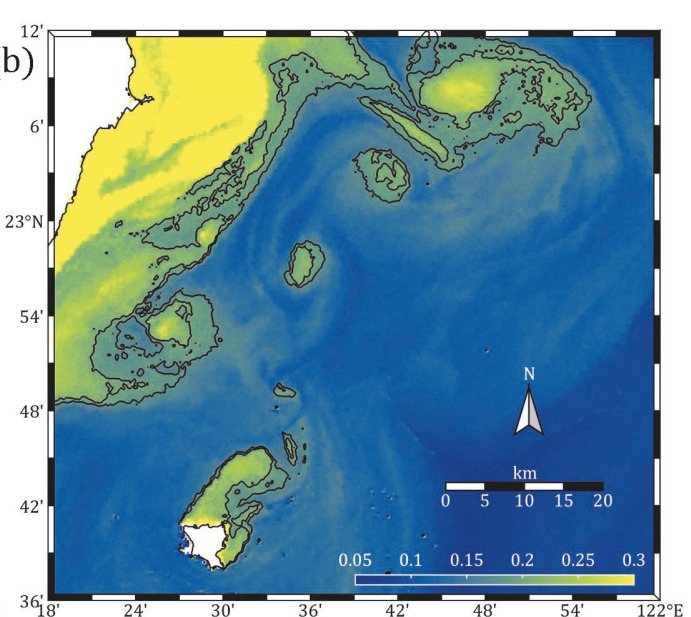

(h)
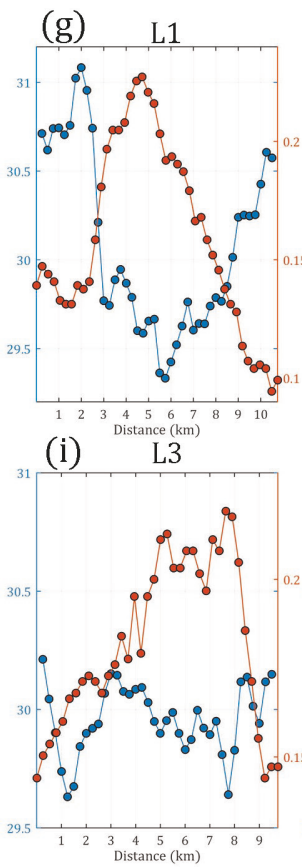

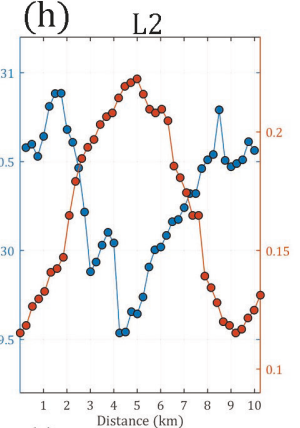

(j)

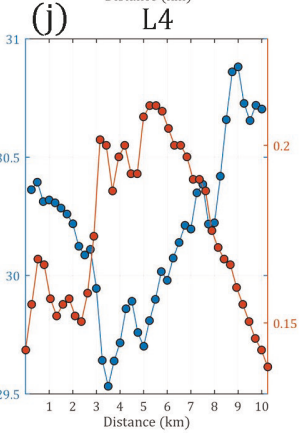

Figure 8. Case of the island vortex train with (a) SST $\left({ }^{\circ} \mathrm{C}\right)$ and $(\mathbf{b}) \mathrm{Chl}-\mathrm{a}\left(\mathrm{mg} / \mathrm{m}^{3}\right)$ obtained from GCOM-C SGLI data taken at 02:07 (UTC), 27 July 2018 (UTC). (c,d) are zoom in on SST and Chl-a of vortex 3. (e,f) same as (c,d), but for vortex 4 . (g-j) are SST and Chl-a values of L1 to L4. The black arrow $\left(22.67^{\circ} \mathrm{N}, 121.67^{\circ} \mathrm{E}\right)$ in $(\mathbf{a})$ is the current velocity from the OSCAR data with a speed of $0.51 \mathrm{~m} / \mathrm{s}$.

The typical Green Island wake (Figure 3) presents with a cold wake extending about $25 \mathrm{~km}$ behind the island. We assumed that the 10 lines cross the wake (L1 to L10 in Figure 3e). If a cruise survey is performed, only one of these lines could be observed in one hour due to the speed limit of the voyage. The lowest SST and the highest Chl-a concentration in the wake region were found at the imaginary lines of L1 to L4. L1 is about $1 \mathrm{~km}$ behind the island, and the SST of the wake area $\left(27.3^{\circ} \mathrm{C}\right) \mathrm{can}$ reach $2.1^{\circ} \mathrm{C}$ lower than that of the Kuroshio water $\left(29.4^{\circ} \mathrm{C}\right)$ as seen in Figure 4. The Chl-a concentration reached $0.23 \mathrm{mg} / \mathrm{m}^{3}$, which was three times that of the Kuroshio water $\left(0.07 \mathrm{mg} / \mathrm{m}^{3}\right)$. We can use this case to quantify the magnitude of the horizontal gradient of SST and Chl-a. From L1 to L4, the SST gradient is about $0.5^{\circ} \mathrm{C} / \mathrm{km}$, and the Chl-a concentration is about $0.025 \mathrm{mgm}^{-3} / \mathrm{km}$. Notably, the dynamic process of a wake can change rapidly, and the seawater structure of the entire wake area will likely change drastically within one hour. It can be seen here that from L7 to L10, there is a small vortex that may detach soon and propagate downstream. Around $23^{\circ}-23.2^{\circ} \mathrm{N}, 121.7^{\circ}-121.8^{\circ} \mathrm{E}$, two 
small vortices were captured (Figure $3 c, f)$. However, we are unsure whether this was caused by the shedding of the vortex train or by the coastal current.

Unlike the low-SST wake in Figure 3, which was concentrated only in a certain range behind the island, Figure 5 shows a case of a vortex train, which the low SST and high Chl-a concentration continue to extend downstream. The imagery line L1 in Figure 5b has the same purpose as L1 in Figure 3e. In this case, a Chl-a concentration of $0.66 \mathrm{mg} / \mathrm{m}^{3}$ was observed, which was eight times the Kuroshio water, and the difference in SST was $2{ }^{\circ} \mathrm{C}$. The distance between the two vortices is about $30 \mathrm{~km}$ (L2 to L4 in Figure 5e). L3 and L4 lines in Figure 5b passed through two vortices. The data sequence shows the situation of a low-high-low SST and high-low-high Chl-a concentration. Since the downstream vortex is affected by seawater mixing, the SST is usually higher than that of the wake close to the island.

A classic state in wake dynamics is illustrated in Figure 6, which was not captured in previous studies on Green Island. With high-resolution satellite data, we can observe the cooling zone transitions on the left and right side of the island wake region (usually corresponding to the magnitude of the vorticity). From the data in Figure 6e, it can be seen that there are two peaks in the low-SST wake region, $28.8^{\circ} \mathrm{C}$ and $28.9^{\circ} \mathrm{C}$, respectively, and the corresponding Chl-a concentrations are $0.24 \mathrm{mg} / \mathrm{m}^{3}$ and $0.20 \mathrm{mg} / \mathrm{m}^{3}$. The left side of the wake region has a lower SST and a higher Chl-a concentration. From the data in Figure $6 \mathrm{f}$, two peaks in the low-SST wake region can be found $\left(28.3^{\circ} \mathrm{C}\right.$ and $\left.27.5^{\circ} \mathrm{C}\right)$, and the corresponding Chl-a concentrations are $0.14 \mathrm{mg} / \mathrm{m}^{3}$ and $0.16 \mathrm{mg} / \mathrm{m}^{3}$. The right side of the wake region has lower SST and higher Chl-a concentration. To understand the wake evolution more clearly, we used the MITgcm model to present the variations in Rossby number $(R o)$ during the wake's dynamic process (Figure 7):

$$
\begin{gathered}
R o=\frac{U}{f L} \sim \frac{\zeta}{f} \\
\zeta=\frac{\partial \mathrm{v}}{\partial \mathrm{x}}-\frac{\partial \mathrm{u}}{\partial \mathrm{y}}
\end{gathered}
$$

where $U$ and $L$ are the velocity and length scales of the phenomenon, $f$ is the Coriolis frequency, and $\zeta$ is the relative vorticity. The quantified vorticity using Ro helps to interpret the eddy strength. A very small $R o$ is typical to general circulation. A very high Ro can be seen in rapidly rotating eddies. The simulation results show that positive and negative vorticity are sequentially detached from each other in a few hours. This clearly illustrates the results we captured from the GCOM-C images (Figure 6). This also demonstrates the importance of being careful when making cruise measurements, because each wake can change quickly, and the water may mix in different vorticity states for each observation station.

An ideal von Carmen vortex street can be seen in Figure 8a,b. Four sub-mesoscale vortices detached from the island to downstream. Vortex 3 (Figure $8 \mathrm{c}, \mathrm{d}$ ) and vortex 4 (Figure 8e,f) were selected for observations, and two imaginary lines that crossed the highest Chl-a position of the vortex were designed. The size of the vortex's core is about $5 \mathrm{~km}$, which is close to the size of Green Island. The maximum Chl-a concentration in both vortices was $0.22 \mathrm{mg} / \mathrm{m}^{3}$. An interesting phenomenon was also seen here. In the vortex core, the Chl-a concentration did not exactly match that of the SST. As a rotating vortex, the SST may increase during the propagation process due to the mixing of the Kuroshio. The SST variation of the vortex in the model experiment is difficult to simulate because it is not known which factors alongside seawater mixing could affect the vortex when it detaches downstream. In the satellite observations, it was often found that vortex street rarely appeared, which was very different from the model simulations [9]. In the next section, the geosynchronous Himawari-8 satellite data were used to analyze and discuss the dynamic process of the vortex train.

\subsection{Temporal Variation and Vortex Trajectory}

The previous section presented the spatial structure of biological hotspots in the wake area, and the dynamic process of the vortex is mentioned in this section. To study the dynamics of island wakes, 
the most important factor is to solve the setting of the two major parameters, the Strouhal number $(S t)$ and the Reynolds number $(R e)$, as well as the propagation velocity of the vortex $\left(U_{e}\right)$. The $S t$ is a dimensionless number describing the oscillating flow mechanisms as:

$$
S t=\frac{L}{T U_{0}}
$$

where $T$ is the vortex shedding period, $U_{0}$ is the incoming current speed, and $L$ is the characteristic length. The $R e$ is an important dimensionless quantity in fluid mechanics used to help predict the flow patterns in different fluid flow situations as:

$$
R e=\frac{U_{0} L}{v_{h}}
$$

where $v_{h}$ is the horizontal eddy viscosity.

With continuous cloud-free data, the trajectory and velocity of the vortex could be tracked and calculated. A vortex has the characteristics of a closed isotherm of SST, and the lowest SST in the eddy can represent its center position [9]. In this way, the trajectory of the vortex can be tracked. An example of two consecutive vortices within $24 \mathrm{~h}$ of SST images is shown in Figure 9, with the temporal ranging from 21:00 (UTC) on 12 July 2016 to 20:00 (UTC) on 13 July 2016. We can see how the wake vortex detached and passed downstream. The first vortex was formed at 23:00 (UTC) on 12 July 2016 (the red star in Figure 9), and the second vortex was formed at 11:00 (UTC) on 13 July 2016 (the red dot in Figure 9), the shedding time interval was 12 h. The vortex detaching happens when the instability disturbances by background flow. The average speeds of the two vortices were $1.21 \mathrm{~m} / \mathrm{s}$ and $1.45 \mathrm{~m} / \mathrm{s}$, respectively. To understand the variations of the sub-mesoscale Green Island vortices, a total of 101 vortex cases from July 2015 to December 2019 were calculated. A total of 78 cases occurred in the summer (June to August). In 101 cases, the average vortex propagation velocity was $0.95 \pm 0.28 \mathrm{~m} / \mathrm{s}$, and the maximum and minimum values were $1.82 \mathrm{~m} / \mathrm{s}$ and $0.31 \mathrm{~m} / \mathrm{s}$, respectively. A total of 101 vortex trajectories and their probability distributions are shown in Figure 10a,b. Figure 10c presents a histogram of property velocity statistics for 101 vortex cases. As mentioned in previous studies [8], the angle of the vortex distribution and the angle of the incoming velocity in front of the island are highly correlated. Therefore, based on the trajectory distribution in Figure 10a, the angle of the incoming current field in front of the island can be estimated. More than half of the vortex cases have propagation velocities between 0.8 and $1.2 \mathrm{~m} / \mathrm{s}$. The probability distribution of the trajectory is shown in Figure 10b. Most of the vortices with low SST and high Chl-a concentrations are concentrated within $30 \mathrm{~km}$ northeast of Green Island. The biological hotspots in the wake area mainly appear in this area of $900 \mathrm{~km}^{2}$ and propagate downstream with the vortex stream. Based on the MCC method, the calculation results show that the average incoming flow velocity $U_{0}$ that caused the vortex shedding cases in Figure 10a is $1.15 \pm 0.22 \mathrm{~m} / \mathrm{s}$. 


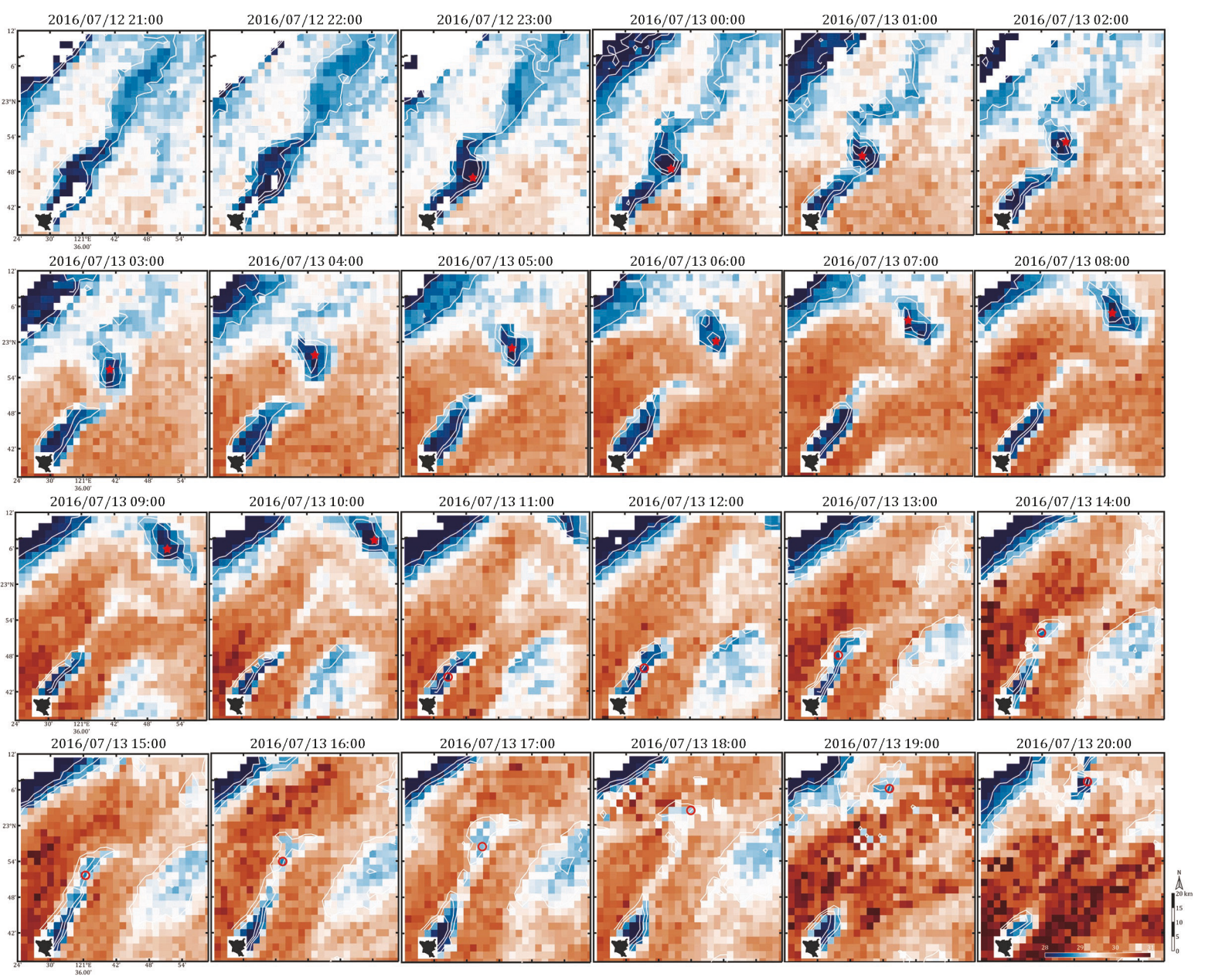

Figure 9. The 24-h continuous Himawari-8 SST images from 21:00 UTC on 12 July 2016 to 20:00 UTC on 13 July 2016. Red stars and red dots represent the center positions of the two vortex cases.
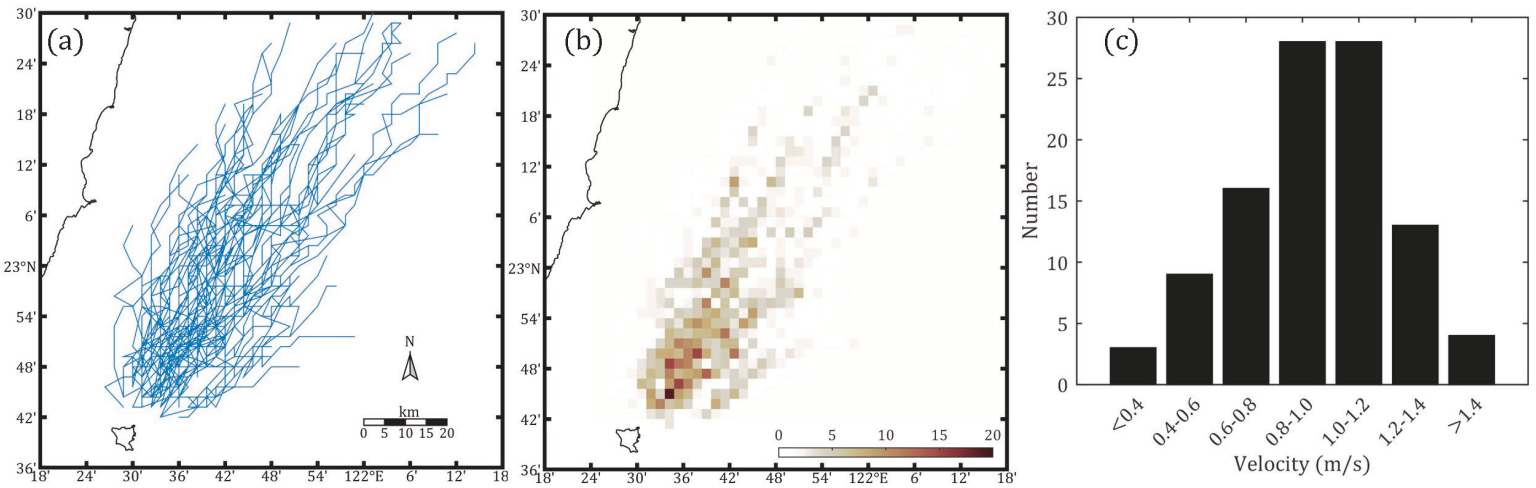

Figure 10. (a) trajectory of 101 vortex cases, (b) the distribution probability (\%) of the vortices for 101 cases, and (c) a histogram of the property speed statistics for 101 vortex cases.

Next, we use the case of vortex shedding to calculate $S t$, and we must determine the time interval between two continuous vortices. Therefore, a total of 38 cases were provided in this study for calculations. The results show that the average vortex shedding period is $14.8 \mathrm{~h}$. Based on the settings of $L=5500 \mathrm{~m}$ and $v_{h}=100 \mathrm{~m}^{2} / \mathrm{s}$, the average $S t$ and $R e$ are 0.114 and 64, respectively, which are consistent with the fitted curve values [27] as shown in Figure 11. 


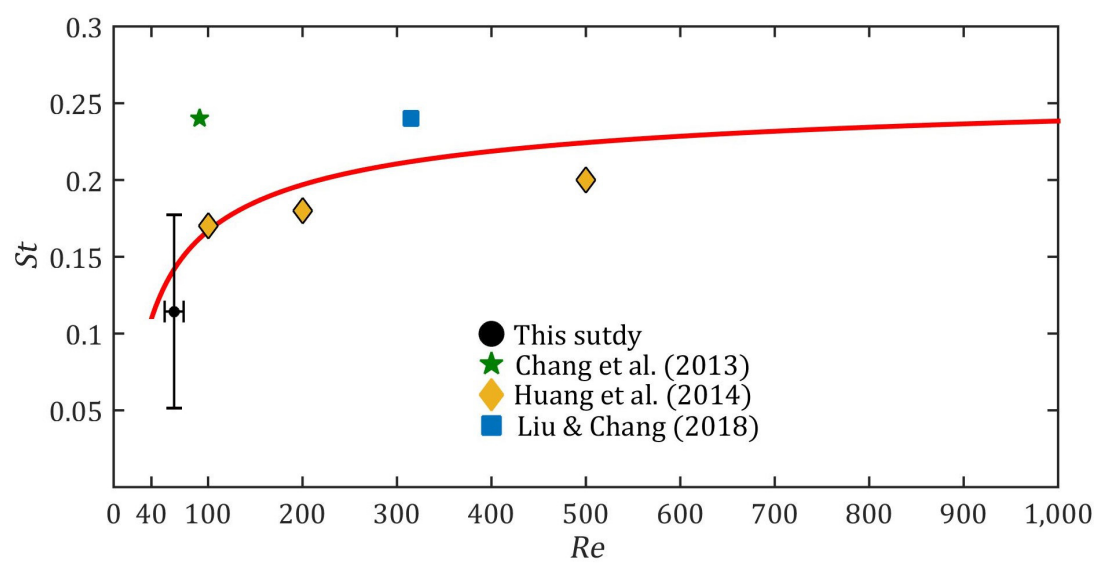

Figure 11. The Strouhal number $(S t)$ versus the Reynolds number $(R e)$ diagram. The point for this study is expressed as the mean value with one standard deviation.

\section{Discussion}

\subsection{The Relationship Between Re and St}

The relationship between Re and St plays a major role in determining island wake patterns, evolution, and vortex shedding. The fitting curve relation between $R e$ and $S t$ for cylinder wakes were formulated as [27]:

$$
S t=0.273-1.11 R e^{-\frac{1}{2}}+0.482 R e^{-1}
$$

In theory, the $R e$ value depends only on the size of $U_{0}$ when focusing on the same obstacle. However, Green Island is an irregular island, and there were differences in the choice of the diameter $(L)$ of the obstacle. According to the measurements from the National Land Surveying and Mapping Center, Taiwan, the size of Green Island is $15.09 \mathrm{~km}^{2}, 4.6 \mathrm{~km}$ wide, $5.2 \mathrm{~km}$ long, and the longest side is about $6 \mathrm{~km}$. Therefore, it is appropriate to choose $L=5-6 \mathrm{~km}$ for research on Green Island. However, some researchers have instead chosen $L=7 \mathrm{~km}$, which indicates a width of $100 \mathrm{~m}$ for the island in the water $[5,14,15]$. It is worth noting that the choice of $L$ will significantly affect the values of $S t$ and $R e$. In addition, the value selection of horizontal eddy viscosity $\left(v_{h}\right)$ when calculating the Re value is a difficult problem to be solved. Since this value is not easy to measure with observations, previous studies have used estimated values. In the open ocean, the $v_{h}$ varies from $10^{2}$ to $10^{5} \mathrm{~m}^{2} / \mathrm{s}$ [28]. For the mesoscale or sub-mesoscale ocean processes, the $v_{h}$ is generally chosen as $10^{3}$ to $10^{4} \mathrm{~m}^{2} / \mathrm{s}[16]$. Next, we sort the data of various researchers and recommend what types of values are most suitable for studying Green Island. Table 1 shows the corresponding data for each point in Figure 11. In this study, $L$ and $v_{h}$ were selected as $5500 \mathrm{~m}$ and $100 \mathrm{~m}^{2} / \mathrm{s}$, respectively. The results of 38 cases showed that the cases fit the equation of the fitted curve. With the average $U_{0}=1.15 \mathrm{~m} / \mathrm{s}$, the average $R e$ is 64 , and the average $S t$ is 0.114 . We recommend that $L$ be selected from $5-6 \mathrm{~km}$. If a larger value of $L$ is selected, the $S t$ may be too large $(>0.3)$. A $v_{h}$ value of $100 \mathrm{~m}^{2} / \mathrm{s}$ is suitable, as a $v_{h}$ value that is too small may cause the $R e$ value to be too large. Although previous studies were based on observational data, there was only one sample. Take the case of this study as an example. If the $v_{h}$ value was chosen to be $15 \mathrm{~m}^{2} / \mathrm{s}$ [14] or even $0.2-7 \mathrm{~m}^{2} / \mathrm{s}$ [15], the points of the case could be far from the fitted curve equation. 
Table 1. Corresponding values for each point in Figure 10.

\begin{tabular}{cccccc}
\hline $\mathbf{L}(\mathbf{m})$ & $\boldsymbol{U}_{0}(\mathbf{m} / \mathbf{s})$ & $\boldsymbol{v}_{\boldsymbol{h}}\left(\mathbf{m}^{2} / \mathbf{s}\right)$ & $\boldsymbol{R e}$ & $S t$ & Reference \\
\hline 7000 & 1.3 & 100 & 91 & 0.24 & {$[5]$} \\
\hline \multirow{2}{*}{5000} & \multirow{2}{*}{1} & 50 & 100 & 0.17 & \\
& & & 500 & 0.18 & {$[6]$} \\
\hline \multirow{2}{*}{5000} & 0.675 & 15 & 315 & 0.24 & {$[14]$} \\
\hline 5500 & $\overline{U_{0}}=1.15$ & 100 & $\overline{R e}=64$ & $\overline{S t}=0.114$ & This study \\
\hline
\end{tabular}

Next, we will discuss the cases in our sample with $R e>40$ (vortex street occurrence) but $S t<0.1095$ (the minimum value of the fitted curve equation). According to our parameter settings, if $R e$ is greater than $40, U_{0}$ must be larger than $0.73 \mathrm{~m} / \mathrm{s}$. The minimum $U_{0}$ in 38 cases is $0.85 \mathrm{~m} / \mathrm{s}$. To make $S t>0.1095$, when $U_{0}=1 \mathrm{~m} / \mathrm{s}, T<13.95 \mathrm{~h}$, when $U_{0}=1.2 \mathrm{~m} / \mathrm{s}, T<11.62 \mathrm{~h}$, when $U_{0}=1.4 \mathrm{~m} / \mathrm{s}, T<9.96 \mathrm{~h}$. According to the field observation data [14], the vortex shedding period is $12 \mathrm{~h}$. However, there are many cases in this study that showed a longer period for vortex shedding, which results in a lower St. According to our observations, a low SST vortex formed over a long period of time, but it did not detach for a long time. This verifies the results of previous studies that have used about 15 years of MODIS SST data to determine that about $87 \%$ of cases feature wakes occurring alone [9]. However, the cause of this situation is still unknown. It may be due to local wind, or it may be due to the seawater mixing at lower depths.

Another interesting feature is the vortex propagation velocity. According to numerical simulations [6], $U_{e}$ is between 0.3 and $0.51 \mathrm{~m} / \mathrm{s}$. Based on a near-shore observation [15], $U_{e}$ is $0.347 \mathrm{~m} / \mathrm{s}$. These two results indicate that $U_{e}$ is only $1 / 3$ to $1 / 2$ of $U_{0}$. However, this study indicates that the average $U_{e}$ is $0.95 \mathrm{~m} / \mathrm{s}$, which is about $83 \%$ of the $U_{0}$ value. In the island vortex of the Luzon Strait, a previous study calculated that $U_{e}$ is about $89 \%$ of $U_{0}$ [16]. We believe that the calculations in this study are reasonable. The previous results may be greatly underestimated because the complete period of the vortex movement is not measured.

\subsection{Seasonal Changes in $U_{0}$ and Chlorophyll-a Concentrations}

The velocity data for OSCAR based on the satellite altimeter, temperature gradients, and wind fields, it can explore seasonal variations. In addition to the Kuroshio being possibly affected by mesoscale eddy invasions [29], the seasonal variation of velocity also significantly affects wake evolution. Figure 12a-c show the distribution of the flow field of the Kuroshio annually and in summer and winter, respectively. Figure $12 \mathrm{~d}$ shows the velocity changes each month. Table 2 summarizes the incoming flow speeds from 2010 to 2019. The fastest incoming flow speed was in July, which was 2.4 times the slowest in November. The Kuroshio is variable in different seasons. In addition to analyzing the changes in SST when observing the development of wakes [9], it is also important to observe changes in Chl-a concentration in the wake region, which may affect the aggregation of phytoplankton and fish populations. Based on the average Chl-a concentration $\left(0.15 \mathrm{mg} / \mathrm{m}^{3}\right)$ in the wake region, we analyzed the percentage of data that exceeds this value in different seasons (Figure 13). Since the surface water is relatively cold, and the wind is relatively strong in winter, more nutritious seawater in the deeper layer was mixed into the euphotic zone near the surface of the ocean, which nourishes the growth of phytoplankton. Therefore, such a broadly high Chl-a concentration is not related to the wake development. In summer, due to the vigorous development of wakes, there is a good chance that high Chl-a concentration could be produced within $15 \mathrm{~km}$ of the lee of the island. 

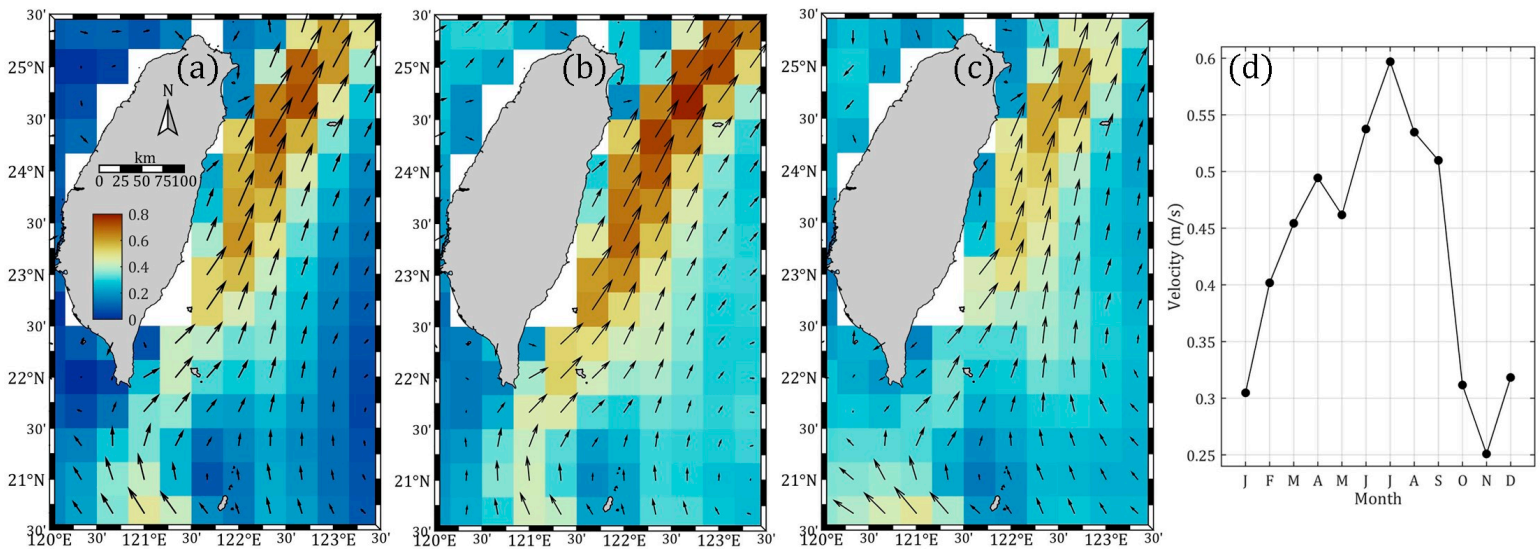

Figure 12. The OSCAR sea surface current velocity from 2010 to 2019, (a) the annual mean for (b) summer and (c) winter and (d) the average of the incoming current velocity for each month.

Table 2. The statistics for incoming speed (m/s) in front of Green Island for the years of 2010 to 2019.

\begin{tabular}{cccc}
\hline & Average & Maximum & Minimum \\
\hline Spring & $0.47 \pm 0.10$ & 0.82 & 0.27 \\
Summer & $0.56 \pm 0.13$ & 0.94 & 0.28 \\
Fall & $0.36 \pm 0.18$ & 0.84 & 0.02 \\
Winter & $0.34 \pm 0.13$ & 0.63 & 0.02 \\
\hline
\end{tabular}

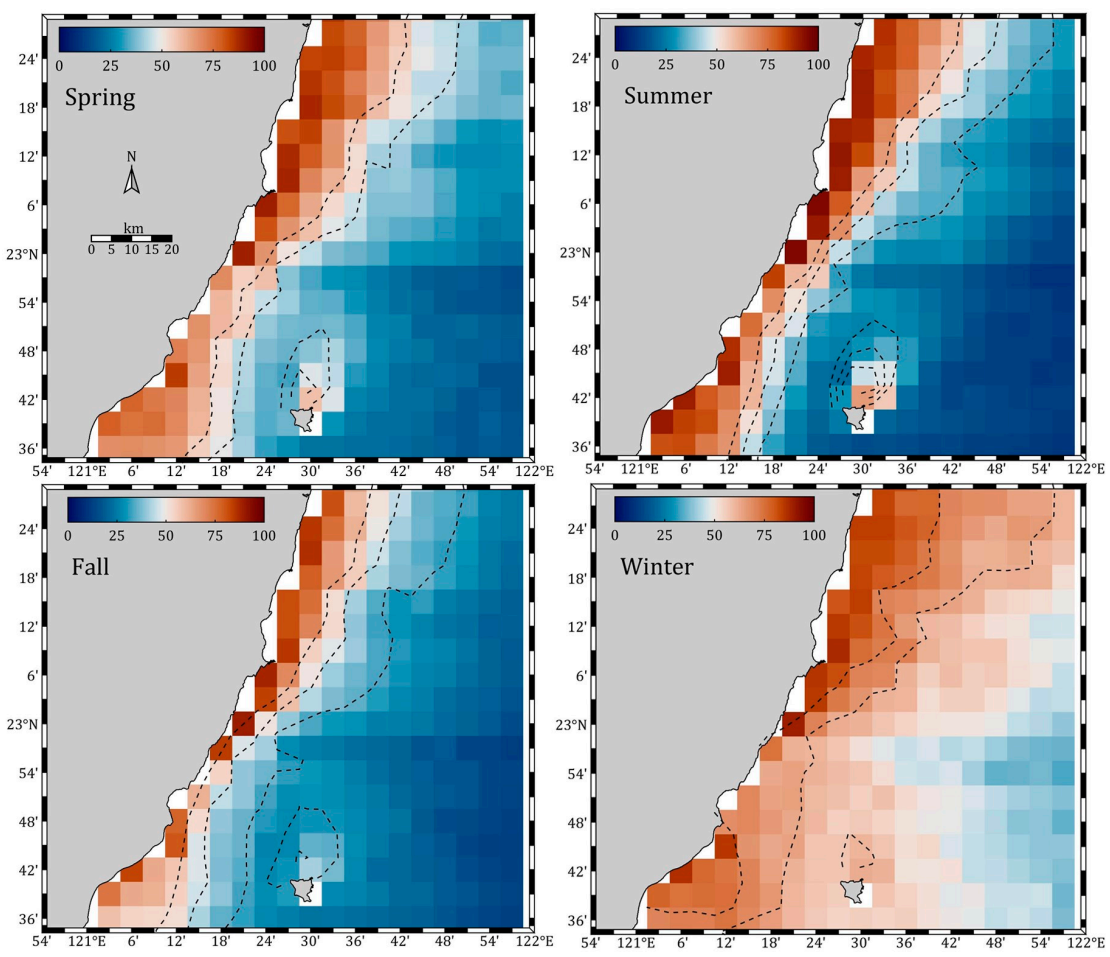

Figure 13. The probability distribution of the Chl-a concentration $\left(>0.15 \mathrm{mg} / \mathrm{m}^{3}\right)$ in different seasons.

Of the 101 vortex trajectories in this study, 78 cases appeared in summer (June to August). Velocity and many missing values in winter due to clouds may be the main factors behind this phenomenon. According to theoretical experiments, when $5<R e<40$, a fixed pair of symmetric vortices occurred, which is also the most commonly observed cold wake formations in the lee of Green Island, when $40<R e<200$, a laminar vortex street occurred, which corresponds to the vortex shedding trains observed in this study. We used the MITgcm model to establish the SST of wake under the same 
ocean conditions in summer but with different incoming speeds (Figure 14). The three incoming speed conditions correspond to $R e$ values of 70,118, and 156, respectively. When $R e=70$, no cold wake is generated, when $R e=118$, the vortex street is generated, when $R e=156$, the area of a cold wake is significantly expanded, and the SST drop is also significantly increased. The physical parameters obtained in this study can improve the establishment of numerical models of wakes. In addition to changes in the incoming speed, the ocean conditions, which include the values of the sea temperature, seawater stratified structures, Kuroshio meander [29], and local wind effects can affect the evolution of wakes. We will conduct simulation studies of different situations in a future study.
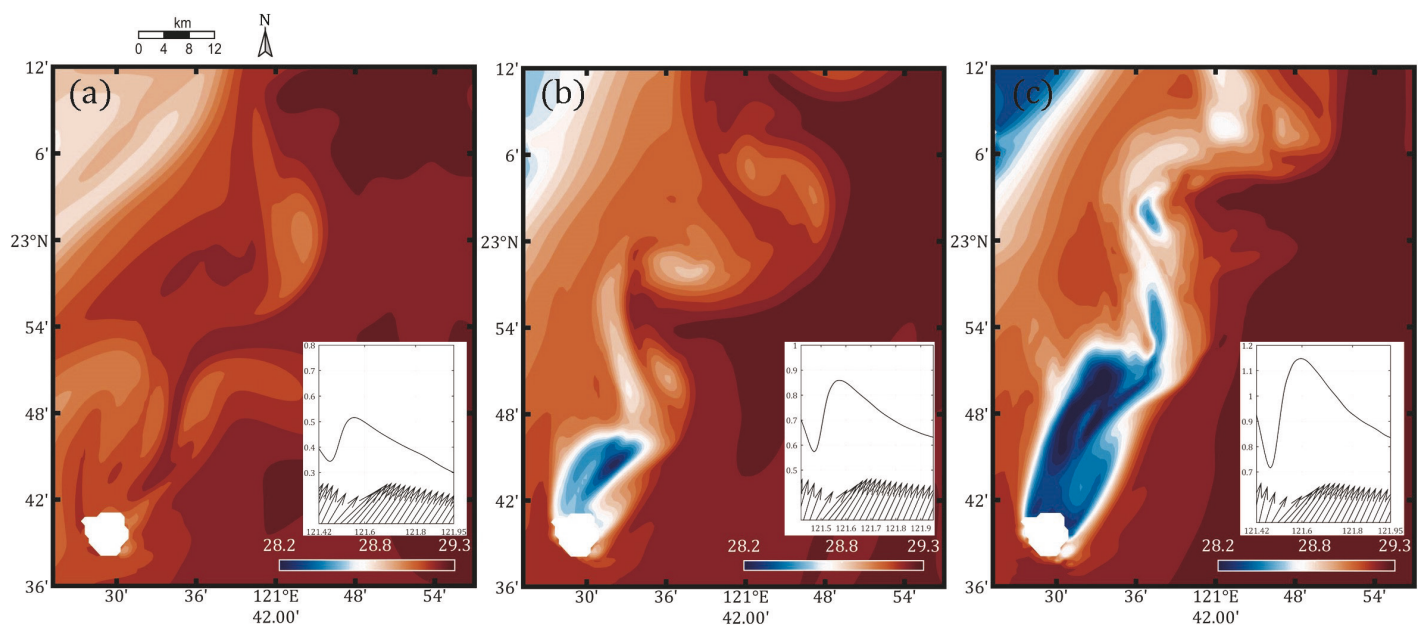

Figure 14. The island wake development from the MITgcm simulation for different Reynolds numbers. (a) $R e=70$, (b) $R e=118$, (c) $R e=156$. The sub-image represents the change in speed $(\mathrm{m} / \mathrm{s})$ along $22.6^{\circ} \mathrm{N}$.

\subsection{Uncertainties, Errors, and Accuracies}

The data of SST and Chl-a used in this study were processed by JAXA. The SST algorithm is based on the method developed for Himawari-8 SST [30]. SGLI SSTs were validated by the comparison with buoy data with $0.8 \mathrm{~K}$ difference, the Himawari-8 had an average SST difference of $0.18 \mathrm{~K}$ with a tropical atmosphere-ocean array [20]. The Chl-a concentration algorithm is developed based on the empirical algorithms for convenient use with the other sensor products, the estimated errors are -60 to $+150 \%$ with in-situ data and MODIS data (https://suzaku.eorc.jaxa.jp/GCOM_C/). In this study, GCOM-C data presented significant variations in SST and Chl-a concentrations in the wake region, and the SST drop and changes in Chl-a were similar to previous in-situ measurements [9]. In addition, this study objectively used the lowest SST in the vortex to track its movement, which was hardly affected by the accuracy of the data. All data have been well managed based on cloud masking classification and decision. In this study, we chose cloud-free data for analysis.

\section{Conclusions}

This study used $250 \mathrm{~m}$ spatial resolution GCOM-C data and 1-h temporal resolution Himawari-8 imagery to analyze the surface structure and dynamic processes of the Green Island wakes. These two sets of satellite data help us more understand the characteristic of sub-mesoscale eddies in the Kuroshio region. Based on the GCOM-C data, we designed observation lines that were different from the cruise observations because every point on the imaginary lines was certain to occur at the same time. Details of the spatial structure of the wake are revealed in this study, including detailed SST and Chl-a changes, the fronts of SST and Chl-a between the wake and Kuroshio water, the distance between two consecutive vortices, the vorticity transition response to sea surface characteristics, and the different structures of SST and Chl-a in the same vortex. Based on the Himawari-8 imagery, the incoming current speed and the propagation speed of the vortex could be calculated. In total, 101 vortex cases from July 2015 to December 2019 were calculated. About 77\% of the cases appeared in summer. The average 
vortex propagation speed was $0.95 \mathrm{~m} / \mathrm{s}$. More than half of the vortices had propagation speeds between 0.8 and $1.2 \mathrm{~m} / \mathrm{s}$. The average incoming surface current speed of Green Island was $1.15 \mathrm{~m} / \mathrm{s}$, which was calculated by the maximum cross-correlation method. In the 38 cases which have two continuous vortices, the average vortex shedding period was $14.8 \mathrm{~h}$, the corresponding average Strouhal number was 0.114 , and the Reynolds number was 64 . In this study, the $S t$-Re fitting curve relation was used to discuss the calculation results of the Green island wake compared to previous studies, and the results suggest that the size of Green Island is suitably selected from 5 to $6 \mathrm{~km}$. Further, the $100 \mathrm{~m}^{2} / \mathrm{s}$ of the horizontal eddy viscosity is still suitable. FIn addition, there is a good chance that a Chl-a larger than $0.15 \mathrm{mg} / \mathrm{m}^{3}$ will be produced within $15 \mathrm{~km}$ at the lee of the island. This study used new remote sensing data to successfully observe and analyze the dynamic processes of the sub-mesoscale vortices. In the future, Himawari-8, the SGLI of GCOM-C, and the Sentinel-3 data will help establish a wake database to be used for ocean sustainability development and assistance in the protection of fishery resources.

Author Contributions: P.-C.H. conceived the project, conducted research, performed initial analyses, visualized data, and wrote the manuscript draft; P.-C.H. and C.-Y.L. processed scientific computing; C.-Y.H. and H.-J.L. Built and processed numerical model; P.-C.H. and C.-R.H. discussed, revised and corrected the manuscript. All authors have read and agreed to the published version of the manuscript.

Funding: This research and the APC was funded by the Ministry of Science and Technology of Taiwan through grants MOST 108-2611-M-019-019 and MOST 108-2811-M-019-506.

Acknowledgments: The authors appreciate all the data use provided from each open database. The Himawari-8 SST and Chl-a data were supplied by the P-Tree System, Japan Aerospace Exploration Agency (JAXA) (http://www. eorc.jaxa.jp/ptree/); the GCOM-C SGLI data were supplied form the Japan Aerospace Exploration Agency/National Aeronautics and Space Administration; the OSCAR ocean currents data were download from NASA PODAAC (https://doi.org/10.5067/OSCAR-03D01); the Sentinel-3 data provided by EUMETSAT for Copernicus; the open historical CTD data obtained from the Ocean Data Bank of the Ministry of Science and Technology of Taiwan (http://www.odb.ntu.edu.tw/en/); and the open source of MITgcm were provided by http://mitgcm.org/.

Conflicts of Interest: The authors declare no conflict of interest.

\section{References}

1. Zeiden, K.L.; Rudnick, D.L.; MacKinnon, J.A. Glider observations of a mesoscale oceanic island wake. J. Phys. Oceanogr. 2019, 49, 2217-2235. [CrossRef]

2. St. Laurent, L.; Ijichi, T.; Merrifield, S.T.; Shapiro, J.; Simmons, H.L. Turbulence and vorticity in the wake of Palau. Oceanography 2019, 32, 102-109. [CrossRef]

3. Kodaira, T.; Waseda, T. Tidally generated island wakes and surface water cooling over Izu Ridge. Ocean Dyn. 2019, 69, 1373-1385. [CrossRef]

4. Tanaka, T.; Hasegawa, D.; Yasuda, I.; Tsuji, H.; Fujio, S.; Goto, Y.; Nishioka, J. Enhanced vertical turbulent nitrate flux in the Kuroshio across the Izu Ridge. J. Oceanogr. 2019, 75, 195-203. [CrossRef]

5. Chang, M.H.; Tang, T.Y.; Ho, C.R.; Chao, S.Y. Kuroshio-induced wake in the lee of Green Island off Taiwan. J. Geophys. Res. Ocean. 2013, 118, 1508-1519. [CrossRef]

6. Huang, S.J.; Ho, C.R.; Lin, S.L.; Liang, S.J. Spatial-temporal scales of Green Island wake due to passing of the Kuroshio current. Int. J. Remote Sens. 2014, 35, 4484-4495. [CrossRef]

7. Zheng, Z.W.; Zheng, Q. Variability of island-induced ocean vortex trains, in the Kuroshio region southeast of Taiwan Island. Cont. Shelf Res. 2014, 81, 1-6. [CrossRef]

8. Hsu, P.C.; Chang, M.H.; Lin, C.C.; Huang, S.J.; Ho, C.R. Investigation of the island-induced ocean vortex train of the Kuroshio Current using satellite imagery. Remote Sens. Environ. 2017, 193, 54-64. [CrossRef]

9. Hsu, P.C.; Cheng, K.H.; Jan, S.; Lee, H.J.; Ho, C.R. Vertical structure and surface patterns of Green Island wakes induced by the Kuroshio. Deep-Sea Res. Part I 2019, 143, 1-16. [CrossRef]

10. Gove, J.M.; McManus, M.A.; Neuheimer, A.B.; Polovina, J.J.; Drazen, J.C.; Smith, C.R.; Merrifield, M.A.; Frienlander, A.M.; Ehses, J.S.; Young, C.W.; et al. Near-island biological hotspots in barren ocean basins. Nat. Commun. 2016, 7, 1-8. [CrossRef]

11. Chen, T.C.; Ku, K.C.; Ying, T.C. A process-based collaborative model of marine tourism service system-The case of Green Island area, Taiwan. Ocean Coast. Manag. 2012, 64, 37-46. [CrossRef] 
12. Denis, V.; Soto, D.; De Palmas, S.; Lin, Y.T.; Benayahu, Y.; Huang, Y.; Liu, S.L.; Chen, J.W.; Chen, Q.; Sturaro, N.; et al. Mesophotic Coral Ecosystems. In Coral Reefs of the World; Loya, Y., Puglise, K., Bridge, T., Eds.; Springer: Cham, Switzerland, 2019; Volume 12, pp. 249-264. [CrossRef]

13. Hsu, T.W.; Doong, D.J.; Hsieh, K.J.; Liang, S.J. Numerical study of monsoon effect on Green Island wake. J. Coast. Res. 2015, 31, 1141-1150. [CrossRef]

14. Liu, C.L.; Chang, M.H. Numerical studies of submesoscale island wakes in the Kuroshio. J. Geophys. Res. Ocean. 2018, 123, 5669-5687. [CrossRef]

15. Chang, M.H.; Jan, S.; Liu, C.L.; Cheng, Y.H.; Mensah, V. Observations of island wakes at high Rossby numbers: Evolution of submesoscale vortices and free shear layers. J. Phys. Oceanogr. 2019, 49, 2997-3016. [CrossRef]

16. Zheng, Q.; Lin, H.; Meng, J.; Hu, X.; Song, Y.T.; Zhang, Y.; Li, C. Sub-mesoscale ocean vortex trains in the Luzon Strait. J. Geophys. Res. Ocean. 2008, 113. [CrossRef]

17. Taniguchi, N.; Kida, S.; Sakuno, Y.; Mutsuda, H.; Syamsudin, F. Short-Term Variation of the Surface Flow Pattern South of Lombok Strait Observed from the Himawari-8 Sea Surface Temperature. Remote Sens.-Basel 2019, 11, 1491. [CrossRef]

18. Liu, J.; Emery, W.J.; Wu, X.; Li, M.; Li, C.; Zhang, L. Computing Coastal Ocean Surface Currents from MODIS and VIIRS Satellite Imagery. Remote Sens. 2017, 9, 1083. [CrossRef]

19. Hu, Z.; Qi, Y.; He, X.; Wang, Y.H.; Wang, D.P.; Cheng, X.; Liu, X.H.; Wang, T. Characterizing surface circulation in the Taiwan Strait during NE monsoon from Geostationary Ocean Color Imager. Remote Sens. Environ. 2019, 221, 687-694. [CrossRef]

20. Ditri, A.L.; Minnett, P.J.; Liu, Y.; Kilpatrick, K.; Kumar, A. The Accuracies of Himawari-8 and MTSAT-2 sea-surface temperatures in the tropical western Pacific Ocean. Remote Sens. 2018, 10, 212. [CrossRef]

21. ESR. OSCAR Third Degree Resolution Ocean Surface Currents; Ver. 1; PO.DAAC: Pasadena, CA, USA, 2009. [CrossRef]

22. Bonjean, F.; Lagerloef, G.S.E. Diagnostic model and analysis of the surface currents in the tropical Pacific Ocean. J. Phys. Oceanogr. 2002, 32, 2938-2954. [CrossRef]

23. Johnson, E.S.; Bonjean, F.; Lagerloef, G.S.; Gunn, J.T.; Mitchum, G.T. Validation and error analysis of OSCAR sea surface currents. J. Atmos. Ocean. Technol. 2007, 24, 688-701. [CrossRef]

24. Marshall, J.; Adcroft, A.; Hill, C.; Perelman, L.; Heisey, C. A finite-volume, incompressible Navier Stokes model for studies of the ocean on parallel computers. J. Geophys. Res. Ocean. 1997, 102, 5753-5766. [CrossRef]

25. Orlanski, I. A simple boundary condition for unbounded hyperbolic flows. J. Comput. Phys. 1976, 21, 251-269. [CrossRef]

26. Klymak, J.M.; Legg, S.M. A simple mixing scheme for models that resolve breaking internal waves. Ocean. Model. 2010, 33, 224-234. [CrossRef]

27. Williamson, C.H.K.; Brown, G.L. A series in $1 / \sqrt{ }$ Re to represent the Strouhal-Reynolds number relationship of the cylinder wake. J. Fluids Struct. 1998, 12, 1073-1085. [CrossRef]

28. Apel, J.R. Principles of Ocean Physics; Academic Press: London, UK, 1987.

29. Hsu, P.C.; Lin, C.C.; Huang, S.J.; Ho, C.R. Effects of cold eddy on Kuroshio meander and its surface properties, east of Taiwan. IEEE J.-STARS 2016, 9, 5055-5063. [CrossRef]

30. Kurihara, Y.; Murakami, H.; Kachi, M. Sea surface temperature from the new Japanese geostationary meteorological Himawari-8 satellite. Geophys. Res. Lett. 2016, 43, 1234-1240. [CrossRef]

(C) 2020 by the authors. Licensee MDPI, Basel, Switzerland. This article is an open access article distributed under the terms and conditions of the Creative Commons Attribution (CC BY) license (http://creativecommons.org/licenses/by/4.0/). 